\title{
Structured Transition of Wind Tunnel Operations Skills from Government- to Contractor-Managed
}

\author{
Steven C. Dunn ${ }^{1}$ \\ Jacobs Technology Inc., NASA Langley Research Center, Hampton, VA, 23681 \\ John J. Schlank \\ Sierra Lobo, Inc., NASA Langley Research Center, Hampton, VA, 23681
}

\begin{abstract}
In 2004, NASA awarded the Research, Operations, Maintenance, and Engineering (ROME) contract at NASA Langley Research Center to a team led by Jacobs Technology, Inc. A key component of the contract was the transitioning of the five large wind tunnel facilities from NASA managed and NASA or NASA/contractor workforces to fully contractor operated. The contractor would manage daily operations while NASA would continue to develop long-term strategies, make decisions regarding commitment of funds and commitment of facilities, and provide oversight of the contractor's performance. A major challenge would be the transition of knowledge of facility operations and maintenance from the incumbent civil servant workforce to the contractor workforce. While the contract has since been modified multiple times, resulting in a blended NASA/ROME workforce across the facilities, the processes developed and implemented to capture and document facility knowledge from the incumbent subject matter experts, build training and certification programs, and grow individual skills across subject areas and across facilities, are worthy of documentation. This is the purpose of this paper.
\end{abstract}

\section{Introduction}

TN response to several external and internal driving forces, NASA/Langley Research Center (LaRC) realigned its Iorganization and business practices in 2003-2004. These driving forces of change included: the President's Management Agenda of 2001, the FAIR Act of 1998, internal efficiency improvements through contract consolidation, and the realignment of the Center's workforce to address skill mix deficiencies and workforce level disparities. As a result, several of the functions that had traditionally been performed by Civil Servants were to be transitioned to the Research Operations, Maintenance, Engineering, and facility related Information Technology (IT) (known as ROME) support service contract, awarded in February 2004 to a team led by Jacobs Technology, Inc.

An aggressive four-year timeline was initially established to transition all tactical operations of five major wind tunnel facilities to the ROME contractor. This transition would occur while the facilities were operating, processes were being established to promote efficient cross-flow of people between facilities, and Civil Servants were exiting to still-to-be-defined positions. From the outset, operational and personnel safety had to be maintained and stewardship of the facilities and customer equipment was paramount. Thus, a structured process was created to define the required skills for each facility, and subject matter experts (SME) for each skill were identified. Also necessary was a thorough knowledge capture effort, with a wide-ranging and detailed training, certification, documentation, and tracking system for each skill area for each person in each facility (and for cross-facilities skill flow). This paper documents the processes, results (including contract/environmental changes), and lessons learned over the first five-year period (2004 - 2009) of the contract.

\footnotetext{
${ }^{1}$ Chief Engineer, ROME Group, NASA Langley Research Center, Mail Stop 267, Hampton, VA, 23692, and AIAA Senior Member.

${ }^{2}$ Branch Manager, Facility Operations Department, ROME Group, NASA Langley Research Center, Mail Stop 389, and AIAA Senior Member.
} 


\section{Initial Effort}

The ROME Statement of Work (SOW) defined 21 skill areas with pre-ROME staffing levels of both contractors and Civil Servants at each of the five main wind tunnel facilities at LaRC. The five facilities were the National Transonic Facility (NTF, the first facility to be transitioned), the Transonic Dynamics Tunnel (TDT), the 4-Foot Unitary Plan Wind Tunnel (UPWT), the 14- by 22-Foot Subsonic Tunnel (14x22), and the 8-Foot High Temperature Tunnel (8-ft HTT). Existing staff at the facilities consisted of employees from nine previous contractor organizations and multiple NASA organizations. A major goal of the ROME contract was to reduce overall staffing through efficient work assignments across facilities, flowing qualified people to the work while ensuring retention of core knowledge at each facility. The initial pre-ROME staffing levels, which took into account work shifts at each facility and required security clearances, is shown in Table 1 . Skill requirements for each wind tunnel are facility functions broken down by major discipline and align with paragraphs of the SOW

\begin{tabular}{|c|c|c|c|c|c|c|c|c|c|c|c|c|c|}
\hline \multirow[b]{2}{*}{ Facility Functions } & \multirow{2}{*}{$\begin{array}{c}\text { Deschipt } \\
n \text { in } \\
\text { Section }\end{array}$} & \multicolumn{2}{|c|}{ NTF } & \multicolumn{2}{|c|}{ UPWT } & \multicolumn{2}{|c|}{$14 \times 22$} & \multicolumn{2}{|c|}{ TDT } & \multicolumn{2}{|c|}{8 Ft. HTT } & \multicolumn{2}{|c|}{ TOTALS } \\
\hline & & Eivil Servar & Contractor & Civil Servan & Contractor & Civil Servan & Contractor & Eivil Servan & Contractor & Civil Servan & Contractor & Eivil Servan & Contractor \\
\hline Operations Management * & 2.1 .1 & 1.0 & 0.5 & 1.0 & & 1.0 & & 1.0 & & 1.0 & & 5.0 & 0.5 \\
\hline Test Engineering * & 2.1 .2 & 2.0 & 2.0 & & 4.0 & 6.0 & & 6.0 & & 1.0 & & 15.0 & 6.0 \\
\hline Fac. Systems Engineering * & 2.1 .3 & & 1.0 & & & & & 1.0 & & 1.0 & & 2.0 & 1.0 \\
\hline Digital Controller Engineering & 2.1 .4 & & & & & & & & 1.0 & & & 0.0 & 1.0 \\
\hline Ground Vibration Test Engineering & 2.1 .5 & & & & & & & & 0.5 & & & 0.0 & 0.5 \\
\hline \begin{tabular}{|l|} 
Data Systems Support * \\
\end{tabular} & 2.1 .6 & 1.5 & 5.0 & 1.0 & & 1.0 & 2.0 & 1.0 & 3.0 & & 2.0 & 4.5 & 12.0 \\
\hline \begin{tabular}{|l|} 
Data Quality Analysis \\
\end{tabular} & 2.1 .7 & & 0.2 & & 0.2 & & 0.2 & & 0.2 & & 0.2 & 0.0 & 1.0 \\
\hline Laser \& Dyn. Data Support & 2.1 .8 & & & & & & 0.6 & & & & & 0.0 & 0.6 \\
\hline Auto. \& Controls System Support * & 2.1 .9 & & 1.0 & 0.2 & 0.5 & 0.2 & 0.5 & & & 1.0 & & 1.4 & 2.0 \\
\hline Instrumentation Sys. Support * & 2.1 .10 & & 5.0 & & 1.3 & 0.5 & 1.0 & 2.0 & & 1.0 & & 3.5 & 7.3 \\
\hline Test Management * & 2.1 .11 & 3.0 & & 0.5 & & 3.5 & & 3.0 & & 1.5 & & 11.5 & 0.0 \\
\hline Test Article & 2.1 .12 & 4.0 & & & 1.0 & & & & & & & 24.0 & 1.0 \\
\hline Technical Operations * & 2.1 .13 & & 12.0 & 4.0 & & 9.0 & & 3.0 & & 4.0 & & 0.0 & 12.0 \\
\hline Electrical System Support & 2.1 .14 & 3.0 & & & 2.0 & 2.0 & & 0.5 & 3.0 & 3.0 & & 8.5 & 5.0 \\
\hline Fluid System Support & 2.1 .15 & & & & & & & & 6.0 & & 4.0 & 0.0 & 10.0 \\
\hline Facility Safety * & 2.1 .16 & 0.8 & & 1.0 & & 1.0 & & 1.0 & & 1.0 & & 4.8 & 0.0 \\
\hline Model Structural Analysis & 2.1 .17 & & 0.6 & & 0.1 & & 0.1 & & 0.1 & & 0.1 & 0.0 & 1.0 \\
\hline Facility Configuration Management & 2.1 .18 & & 1.5 & & & & & 0.5 & & & 2.0 & 0.5 & 3.5 \\
\hline Facility and Test Documentation & 2.1 .19 & & 0.5 & & & & & & & & & 0.0 & 0.5 \\
\hline Facility Coordination & 2.1 .20 & & 0.5 & 0.5 & & 0.5 & & 1.0 & & 0.5 & & 2.5 & 0.5 \\
\hline Facility Scheduling and Integration & 2.1 .21 & & 1.0 & & 0.5 & & 1.0 & & & & & 0.0 & 2.5 \\
\hline Totals & & 15.3 & 30.8 & 8.2 & 9.6 & 24.7 & 5.4 & 20.0 & 13.8 & 15.0 & 8.3 & 83.2 & 67.9 \\
\hline Total Facility Staff & & & & a & & & & 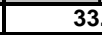 & & & & 15 & \\
\hline
\end{tabular}

* Facility Functions that require security clearance

The above staffing levels are adequate to staff the designated facilities for operations at $100 \%$ of operational capacity

Current facility shifts for the major research facilities are furnished below:

a) NTF: two 8-hour shifts

b) UPWT: a single 8-hour shift

c) 14x22: two 8-hour shifts

d) TDT: two 8-hour shifts

e) 8 Ft. HTT: a single 8-hour shift

In addition, the Government will notify the Contractor of any changes to the research testing requirements for each facility.

Table 1. Major Research Facility Staffing Levels at the Start of the ROME Contract

In addition to providing support for operations in these five facilities, support was also required for the Langley 16-Foot Transonic Tunnel (16-ft TT - planned to be closed later in 2004), the 0.3-Meter Cryogenic Wind Tunnel (0.3-M TCT), and up to twelve other smaller facilities across the Center. Phase-in of the contract occurred from February through April 2004, with contract start on 1 May 2004. During phase-in, interviews of facility staff (Civil Servants and contractors) were conducted to identify the people and personal skill sets associated with the numbers in Table 1, including a first cut at identifying the SME's. Eventually every candidate who applied, both incumbents and outside applicants (with resumes that matched projected needs), were personally interviewed and considered for employment (with incumbent personnel getting the preference if their skill set matched a need). This process provided data to realize an improved staffing chart, documenting a matured understanding of proficiency needs and existing availability of matched skill sets (people) for each skill/facility position.

A corollary effort was to gain an understanding of the documentation (procedures, work instructions, drawings, formal training) associated with the operation and maintenance of each facility and to align that documentation with the various skill areas. Degree of documentation varied widely across the facilities, with the NTF and the 8-ft HTT having the most robust recordkeeping - not surprising given the inherent risks associated with cryogenic operation 
at the NTF and high energy flow media used at the $8-\mathrm{ft}$ HTT. In many skill areas, operation was heavily reliant on the experience of long-time SME's, with limited documentation but high levels of expertise; these would be critical areas for knowledge capture and documentation.

\section{Early Implementation Issues}

Following the bulk of the phase-in hiring process (although this process continued well past the start of the contract), individuals

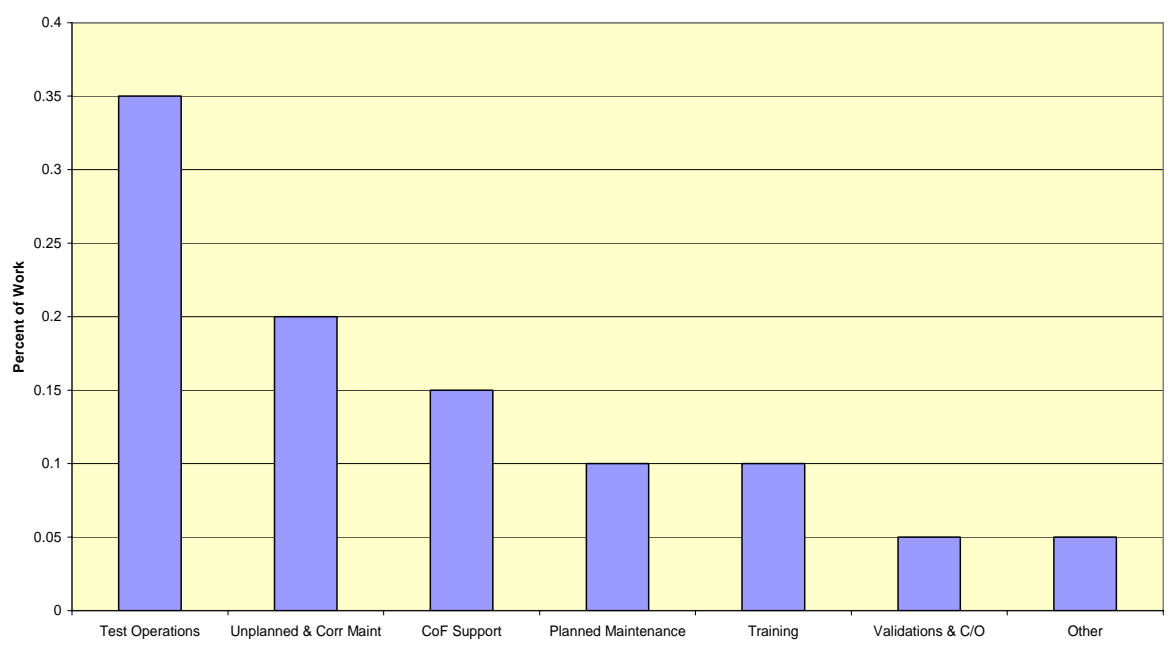
were mapped to skill areas with the proficiencies identified for all five facilities based on past performance. The first priority was to ensure a qualified staff, consisting of a blended contractor and civil servant workforce, was in place at each facility to conduct safe and effective operations on 3 May 2004 - the first business day of the contract. Indeed, all five facilities plus the 16-ft TT and the 0.3-M TCT facilities were in operation (testing) on that first day and were successfully supported.

Overlaying ongoing operations were transition activities at the NTF. Each facility transition was treated as a project, with defined requirements and a verifiable implementation plan. This plan for the NTF was in draft form at contract start and took several months and multiple revisions before all parties signed approval. The transition plan utilized a gap analysis that first identified skill development needs and then addressed how to meet those needs. The approach taken was not to just train new individuals into old 'slots', but to understand the work and design a skills approach to meet specific needs. Within each of the skill areas were different applications based on the type of work. One breakdown of work type at a high level was based on operational mode and is shown in Figure 1.

The end state was defined by laying out the skill needs for each work activity being performed during a typical, but fairly heavily loaded, day in the NTF. This is presented in Table 2. One caveat was that the loading would likely fluctuate, with the ebb or surge managed by crossflowing work and people between facilities. A second caveat was the needed integration of planned implementation of process streamlining and improvements - it was not just transitioning of existing processes. As the transition progressed, implementation of process improvements within the NTF and across all facility operations was achieved.

The initial timeframe for the NTF transition suggested completion nine months after contract start. This aggressive

\section{Table 2. Projected Future State of NTF Staffing at the End of the Transition}

\begin{tabular}{|c|c|c|c|}
\hline \multicolumn{2}{|c|}{ Tunnel Ops (2 Shifts) } & \multicolumn{2}{|c|}{ Model Buildup (1 Shift) } \\
\hline 3 & Mechanical Operators & 1 & Test Engineer \\
\hline 2 & Mechanical Techs & 2 & Mechanical Techs \\
\hline 1 & Electrician & 1 & Instru Tech \\
\hline 1 & Test Director & 0.5 & Instl Engineer \\
\hline 1 & Test/Project Engineer & 0.5 & Software \\
\hline 1 & Video Technician & 0.1 & Stress Analysis \\
\hline 1 & Computer Operator & & \\
\hline 1 & Instrumentation Tech & 5.1 & Total \\
\hline 0.5 & Info Tech & & \\
\hline 0.5 & Data Reduction & & Post-Test \\
\hline 0.5 & Facility Safety Head & 0.5 & Facil Sys Engineer \\
\hline 0.25 & Instru Engineer & $\begin{array}{l}0.5 \\
0.5\end{array}$ & $\begin{array}{l}\text { Post-test Data Pack } \\
\text { Test Eng }\end{array}$ \\
\hline 12.75 & Total (one shift) & & \\
\hline 25.5 & Total (two shifts) & 1.5 & Total \\
\hline & ombined/Totals & & \\
\hline 39.3 & Contractor & & \\
\hline 1 & Civil Service (Facility Manager) & & \\
\hline 1 & Civil Service (Data Manager) & & \\
\hline 41.3 & Total & & \\
\hline
\end{tabular}

3

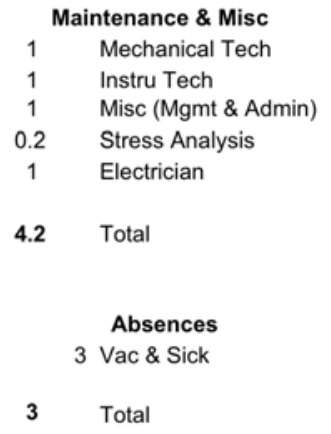

American Institute of Aeronautics and Astronautics 
target was based on the expectation that since a large portion of the workforce at the NTF was already made up of contractors, the transition could happen quickly. But very early into the transition project, a number of challenges (now lessons learned) were placed before the project team, resulting from both planning assumptions and unplanned events:

1) The cultural impact on individuals retained from the previous contracts mixed with multiple NASA organizations was underestimated. Work rules and practices had developed over the years that resulted in extensive sequential operation - handoff from one area of responsibility to another. Camaraderie existed between the staff personally, but the culture was one of functional area accomplishment.

2) The expectation that a significant portion (perhaps up to half) of the workforce required for transition would be supplied by former NASA civil servant technicians and engineers was unfounded. There was little to no incentive for individuals to leave NASA to go to the ROME contract; indeed, there were financial and job security disincentives. This caused a significant lag in both hiring staff and getting them trained to assume transitioned responsibilities (it was thought the NASA transfers could happen fairly quickly and individuals would bring significant job specific skills and knowledge with them).

3) NASA didn't have an clearly communicated transition plan in place for the civil servants whose jobs were being transitioned to the contractor. This caused a disincentive to provide contractor training for civil servants whose jobs were being transitioned to contractors. Mostly, this was an issue for NASA management.

4) Combining with challenge 2 above, contractor senior management was too cautious with the staffing budget, limiting hiring until true personnel requirements per facility was better recognized, and a more complete understanding of civil servant transfers was gained. The contractor, in hindsight, should have kept up an aggressive search and hire process for people with the fundamental and specialized skills that would be needed.

5) Exacerbating the hiring situation was a very hot job market. Experienced engineers and technicians were in high demand in 2004. Finding qualified people and then offering competitive salary and benefit packages was time-consuming and challenging (that was the responsibility of already very busy, lean-staffed contractor management team).

6) At the start of the contract, NASA provided only one "cryogenic-qualified" civil servant test engineer at the NTF. Because testing and other assigned duties took a significant portion of time, knowledge capture and training output was limited (most knowledge capture and training was provided by a part-time contractor test engineer).

7) One week into the contract, the only full-time contractor senior test engineer (from the incumbent workforce) turned in their resignation. Compounding the effect was that the individual was also the assigned project manager for the NTF transition.

Later in the transition process, additional challenges occurred:

8) The exit criteria for transition took a considerably longer time to finalize than expected, causing a delay in the release of the plan and its complete implementation. After approval, the plan still experienced several revisions per customer request. These changes, while improving the product (qualified, certified workers in a facility team environment), added significant scope (and time and cost) to the effort.

9) Nine months into the contract, NASA Langley experienced a budget cut, requiring a severe reduction in force on the ROME contract and a halt or slow-down to many transition activities.

The delay in defining the exit criteria was an evolutionary process of developing and identifying the training and certification requirements for each skill area. As knowledge capture was accomplished, including the gathering of applicable existing documentation, it became obvious that a robust process would add considerable work (and scope) to the planned effort. The NASA management position was that it was better in the long run to get it right (and take longer) than to limit the effort to meet an arbitrary deadline. Combined with the above listed challenges, especially limitations resulting from the budget cuts, the NTF transition was not formally completed until September of 2007.

The training and certification process continued to evolve during each facility transition. A transition team was assembled to lead knowledge capture documentation, formal education and experience requirements, training and personnel certifications. While process documentation in the form of operational procedures and work instructions at the NTF was robust, limited documentation for skill requirements existed. The team developed a process that could be used at any facility.

In the summer of 2006, transition began for the $14 \times 22$ facility. In many ways, the transition team was able to build momentum more quickly than at the NTF: tools and lessons from the NTF experience could be applied, staffing up for transition was well along, the government had assigned a transition manager to lead support from the 
civil servants at the facility, and the basic facility operation was less complex than at the NTF. However, the facility capabilities were very diverse, including extensive test support systems and multiple test techniques. Overall, processes were less documented, relying heavily on the memories of key engineers and technicians - so again, extensive input and new process documentation was required from these SME's.

In 2008, skill transition began at the Transonic Dynamics Tunnel. The 14x22 transition was nearly complete and activities would continue there until they were closed out. Staffing up had begun at the TDT at transition start, but budgetary pressures caused a slowdown from the latest plan and SOW revision. Additionally, new NASA management was rethinking the transition process and outcomes as defined in the SOW. Consequently the transition process was greatly modified, moving from a turnkey approach to contractor management of all tactical operations to a more blended workforce approach with NASA ultimately in charge of processes. But the tools developed from the skill transition remained - still very important in regard to documenting processes for long-term knowledge retention, for ensuring facility workers were qualified for needed tasks, and for configured process control. The remainder of this paper will describe the skill transition process as it evolved at primarily the NTF and $14 \times 22$ facilities.

\section{Define Capabilities and Associated Skills}

The skill requirements were organized using the 21 categories defined in the SOW. Each facility was assessed in terms of its current state and a designed end state, with initial staff (both contractor and civil servant) and end state (contractor) personnel identified by name and skill proficiency. The end state skill needs were developed by the contractor and then iterated with NASA management. NASA had the responsibility to ensure the contractor was providing the requisite skills at appropriate proficiency levels to accomplish the work, so a verification process (including exit criteria) for each skill was part of the design.

Skill proficiency needs were developed using a combination of interviews with existing SME's and NASA supervisors, compilation and review of existing procedures, work instructions, and drawings, identification of knowledge and documentation gaps, and inputs from ROME management on additional needs. In alignment with Langley Center Procedures ${ }^{1}$, each skill area contained three levels of proficiency (not counting entry level employees with no pertinent experience):

Level 1: Subject matter expert. Qualified to oversee, train, and certify proficiency Level 2 and 3.

Level 2: Qualified to accomplish independent work. Can oversee work of proficiency Level 3.

Level 3: Qualified to accomplish work with supervision from a Level 1 or Level 2 certified employee.

Entry level: New hire with no pertinent experience at this skill area. Required to work as a helper and to train for Level 3 certification.

The overall process turned out to be iterative, with proficiency level exit criteria evolving as training and certification content was developed. The incumbent process, on the other hand, utilized extensive on-the-job training over a period of time combined with procedures and work instructions, which placed a high importance on the individual knowledge of key people for processes and specific work requirements. Thus, many of the processes were not documented. This placed an emphasis, for those knowledge areas, on the interviews of SME's.

Skill area SME's were initially identified by NASA management and additional SME's were identified by ROME supervisors and managers as familiarity with facility workforces grew. Interviews with existing skill area SME's typically occurred in a series of encounters, ranging from exhaustive process reviews, including identification of applicable work documents, to specific technique questions.

The task was to focus on managing the process of knowledge capture, documentation development of skill-area training and certification methods (proficiency level and exit criteria), tracking of progress for each individual, and tracking progress toward meeting exit criteria for each skill area in a facility. The team was located on-site at the primary facility in transition, though typically work occurred concurrently with closeout of a previous transition or planning and initial execution of an upcoming transition. Progress, in the form of a matrix of names versus status (current certification level) of specific requirements for a particular skill area was posted. Table 3 provides an example of a portion of one of the progress charts.

The required number of employees possessing each skill area was based on projected workload of each facility. Also taken into consideration was the number of work shifts per day (nominally eight hours per shift and one or two shifts per day), amount of parallel operations (pre-test and post-test work occurring concurrently with an active test in the tunnel), maintenance support, training, and support to major infrastructure investments work. The mix of 


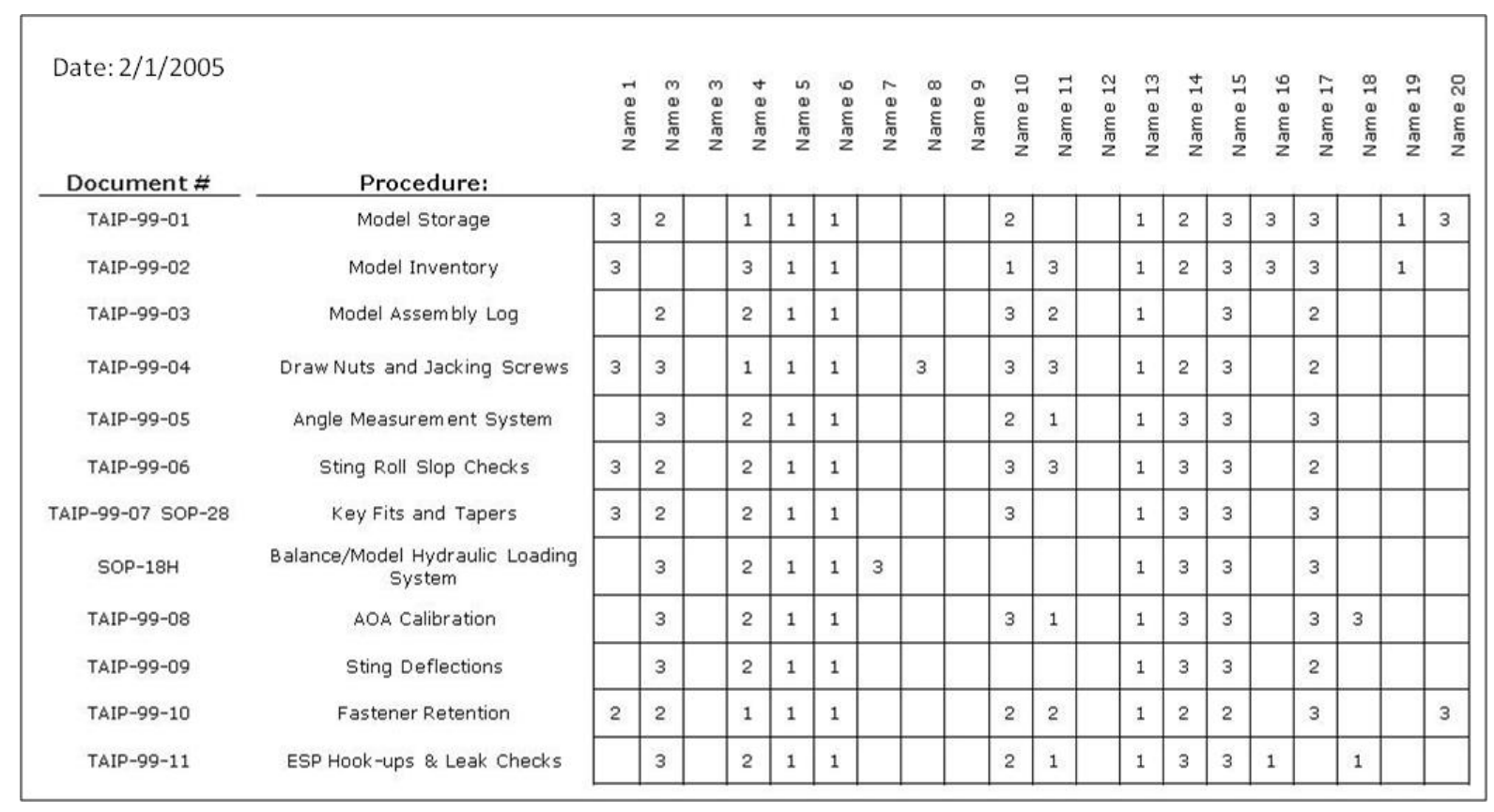

\section{Table 3. Process Skill Level Tracking Table}

skills, both types and quantities, was designed based on past experience, with tuning to account for current conditions and implemented process improvements. Initially, the timing of skill area transitions was based on the most logical path within the timeframes established by the SOW. When actual conditions were defined (degree of documentation, budget constraints, ongoing test operations, and other variables), skill transition was tuned to adapt to those conditions while meeting work safety and quality requirements.

In conjunction with SME interviews and skill definitions, the team identified documentation needs for each facility whether it meant creating new or updating old information. New documentation resulted largely from both development of the training material in support of exit criteria and undocumented processes identified from the SME interviews. Existing documentation was obtained from multiple locations: the Langley Configuration Management On-Line system (a primary location for configured drawings and procedures), the facility library, the Facility Resume (a notebook or set of notebooks containing specified facility safety and operational information), aeroCOMPASS (a Langley online database system containing extensive facility test-related information), the Langley Management System (the online system containing NASA and Langley Center procedures), and individual (usually SME) personal computers. A list was prepared for each skill area and was populated as information was collected and included responsible parties and due dates for processes needing new or updated records.

Training plans were developed for each level of each skill area in a building block approach - thus, even incumbent contractor SME's were required to accomplish the entirety of the work to meet Level 1 exit criteria for a particular skill. Training plan content consisted of a combination of documentation review, process demonstrations, and defined amounts of time or cycles on observed (by higher, certified, skill level personnel) work.

Training occurred in parallel with ongoing test operations, offering great opportunities to gain experience on a variety of test techniques over multiple test project life cycles. Training on skill fundamentals, which necessarily had to precede hands-on, or on-the-job training (OJT), was integrated with test schedules. OJT was planned to take advantage of ongoing test activities, including scheduling of higher skill level mentors/observers. OJT was tracked by skill area and name, for both trainees and mentors/observers.

Some test activities were scheduled just to provide training opportunities, but these were limited due to cost. In the NTF, the facility utilizes a periodic check standard test to ensure no significant shifts in data quality occur over time. The check standard tests are also used before and after major facility modifications that may affect tunnel flow quality. Several of these tests, which provide a full test project cycle over a short period of time, were utilized as training opportunities. When utilizing these types of tests, the transition team had to be careful when adding any extra training elements to the test program to insure that accurate tunnel performance measurements were maintained and not compromised by modifications to standard procedures. 
Certification for a skill level resulted from meeting defined exit criteria. The transition team agreed that defining exit criteria and associated training plans was the most difficult task of preparing the Transition Management Plan for a facility. In terms of risk management, to what level did someone need to be qualified and how would that skill level be verified? Since this was largely a new approach using much new documentation, gaining concurrence from NASA management and SME's was an iterative process that delayed the approval of both the NTF and $14 \times 22$ Transition Management Plans. In both cases, there was concurrence by all parties on a good deal of each plan, so transition work proceeded while exit criteria were being finalized.

Since much of the training was occurring while remaining portions of training plans were being developed, the process was evolutionary and iterative. Training plan content had a strong tendency to grow as additional people (NASA management and SME's) were consulted - understandable when considering NASA was turning over process responsibilities for high value, one-of-a-kind, key national assets. Perhaps the best example of this growth was with the training plans for $14 \times 22$ test engineers. Test engineers are required to understand the facility as a system, including subsystems and how they interact. Add a test article to the system and complexity increases. As previously noted, the $14 \times 22$ facility included multiple test techniques, each requiring different equipment and processes - this adds permutations to training and to an engineer becoming competent in these techniques. One part of each test engineer's instruction was attendance at a series of sessions presented by SME's (from both NASA and the ROME contractor). A total of 44 sessions were presented (subject areas shown in Table 4), by 21 speakers. An added bonus was that these sessions were advertised in advance and opened to all comers, so average attendance of both contractors and civil servants was 12 people per session. But this excellent set of training sessions grew over time, extending the schedule for formally certifying the test engineers.

All exit criteria included the defined training plans and many included additional requirements related to skill responsibilities and facility test techniques. Where multiple test techniques existed, an employee would incrementally achieve certification as exit criteria were met for each technique. For example, the NTF operates in either air or cryogenic nitrogen modes. A test engineer, as part of his or her exit criteria, was required to conduct a test (while under observation from a certified test engineer) in each operational mode before being eligible for certification in that mode.

\begin{tabular}{|l|l|}
\hline \multicolumn{2}{|c|}{ 14x22 Training Session Subject Areas } \\
\hline $\begin{array}{l}\text { Basic Aero, 14x22 Nomenclature, Data Reduction, Test } \\
\text { Section Condition Calculation }\end{array}$ & WICS Hardware Overview \\
\hline Tunnel Calibration and Characterization & Model Safety Box Overview \\
\hline NEFF A/D Converter & ESP System and Use at 14x22 \\
\hline Data Reduction I & DAS Graphics \\
\hline DAS Approach to Balance Interactions & Fixed Transition \\
\hline Data Reduction II & Model Height Set Up \\
\hline Longitudinal S\&C & $14 x 22$ Facility Overview Tour (Outside) \\
\hline Sting Deflections & Flow Angularity, Tare \& Interference \\
\hline 14x22 Facility Overview Tour (Inside) & Test Process I \\
\hline Test Process II & Force \& Moment Data Processing at 14x22 \\
\hline Base Pressures & $14 x 22$ Facility Archive \\
\hline AeroCOMPASS & Balance Interactions \\
\hline Compressor Station Overview & DAS Problems 7 \& 8 Review \\
\hline Facility Resume, SAR, Safety Briefing & Q-Flex \\
\hline Propulsion Simulation Using HPA at the 14x22 & $14 x 22$ High Pressure Air Station Details \\
\hline Flow Visualization & Acoustic Testing at 14x22 \\
\hline Introduction to DESL & DESL Display \\
\hline DESL Analysis & Aerial Lift \\
\hline Shop Machine Safety & Wind Tunnel Balances \\
\hline Transducers/Strain Gages/Thermocouples & Wall Corrections \\
\hline Barocell and Instrumentation Rack & Air Station \#2 \\
\hline Instrumentation Cables from Model to DAS & Control Room Video System \\
\hline Flight Dynamics Branch Research Overview & \\
\hline
\end{tabular}

Table 4. 14x22 Training Session Subject Areas 
The most critical skill areas, in term of risk management, required a board certification following the accomplishment of all other requirements. These skill areas were facility safety heads, test engineers, facility coordinators, and compressor station operators. Boards consisted of knowledge-area appropriate NASA and contractor management and SME's. Questions were prepared in advance and individuals were required to present satisfactory answers. The boards were pass-fail, with only areas that were deemed unsatisfactory requiring a retest. It should be noted that the Facility Safety Head (FSH) was required to take four board exams, each covering a defined portion of facility knowledge. Since the FSH is the final go-to person for approval of process deviation, he or she must have intimate knowledge of facility systems down to the equipment level and how it all interacts.

All skill/level certifications require approval by key facility personnel. For many, this process can be intimidating and care is given to prepare the candidate for the process, structuring the amount of material covered per board review as appropriate for the individual.

\section{Results}

The process of understanding skill content, capturing existing knowledge, documenting that capture, developing training plans, and developing/defining skill level exit criteria evolved across the transition process as complexities were understood and lessons were learned. The transition process was turbulent, with declining budgets stretching out schedules while NASA management changes revised transition and skill transfer direction and content. Still, the need to capture knowledge at facilities and provide qualified workers with complex skill sets was accomplished.

The NTF and 14x22 transitions were completed with qualified/certified people in all required positions. During an ISO9001:2000 audit, the skill transition process in the NTF was cited as a best practice by the auditor. The process has successfully been applied to all contractor personnel at the Langley compressor station-an extremely critical complex that supplies high-pressure air to many of the test facilities on the Center. The very robust certification process for the FSH positions was also (in addition to the NTF and 14x22) successfully implemented at the UPWT, TDT, 8-FT HTT., and the compressor station. Three ROME Facility Safety Heads have received Langley FSH quarterly awards, with one also receiving the annual award. The process is currently being implemented for ROME contractor personnel at the TDT.

\section{Looking Ahead}

In response to a generally declining operations tempo, NASA Langley wind tunnel operation is moving toward a block operations staffing model. Block operations defines a work crew, with particular skill sets, that rotates between two or more facilities as workload dictates. This methodology retains capabilities while reducing costs by lowering available test capacity, with staffing limiting capacity. This cross-flow of workers between facilities was also part of the original transition design, but block operations accelerates the flow. A study on how to accelerate training and certification of workers qualified for operations in multiple facilities is currently underway. This paper is targeted at documenting the transition process and lessons learned as a starting point for that study.

A number of questions remain regarding the future for skills management following the termination of overall facility transitions - the new study is expected to answer these questions for a blended workforce and block operation of facilities:

- How will the gains in knowledge capture, training, and certification of workers be sustained over time and as new workers replace existing ones?

- Will this or some other process be used to capture knowledge, train, and certify workers at other facilities and as block operations proceed?

- Will it be the same for contractor and civil servant personnel?

- How will this work be funded?

Overall, the process developed for the facility transition process was very difficult, with much of the difficulty due to the changing environment. It did deliver in the end, providing a quality workforce with measurable and certified abilities at key NASA facilities. The process developed for this effort provides a number of tools that could be applied in a variety of different operational environments and will afford a solid starting point for the new personnel qualification study.

\section{References}

${ }^{1}$ Langley Procedural Requirements, LPR 1740.7, Process Systems Certification Program, Effective 2/24/05 - 2/1/12. 